\title{
Effect of Sipjeondaebo-Tang on Cancer-Induced Anorexia and Cachexia in CT-26 Tumor-Bearing Mice
}

\author{
Youn Kyung Choi, ${ }^{1}$ Ki Yong Jung, ${ }^{2}$ Sang-Mi Woo, ${ }^{1}$ Yee Jin Yun, ${ }^{1}$ Chan-Yong Jun, \\ Jong Hyeong Park, ${ }^{2}$ Yong Cheol Shin, ${ }^{1}$ Sung-Gook Cho, ${ }^{1}$ and Seong-Gyu Ko ${ }^{1}$ \\ ${ }^{1}$ Department of Preventive Medicine, College of Korean Medicine, Kyung Hee University, 1 Hoegi-dong, Dongdaemun-gu, \\ Seoul 130-701, Republic of Korea \\ ${ }^{2}$ Department of Oriental Internal Medicine, College of Oriental Medicine, Gachon University, Seongnam, Republic of Korea
}

Correspondence should be addressed to Seong-Gyu Ko; epiko@khu.ac.kr

Received 17 February 2014; Accepted 23 April 2014; Published 14 May 2014

Academic Editor: Bing Du

Copyright (C) 2014 Youn Kyung Choi et al. This is an open access article distributed under the Creative Commons Attribution License, which permits unrestricted use, distribution, and reproduction in any medium, provided the original work is properly cited.

Cancer-associated anorexia and cachexia are a multifactorial condition described by a loss of body weight and muscle with anorexia, asthenia, and anemia. Moreover, they correlate with a high mortality rate, poor response to chemotherapy, poor performance status, and poor quality of life. Cancer cachexia is regulated by proinflammatory cytokines such as interleukin-6 (IL-6), monocyte chemoattractant protein-1 (MCP-1), and tumor necrosis factor- $\alpha$ (TNF- $\alpha$ ). In addition, glucagon like peptide-1 (GIP-1), peptide YY (PYY), ghrelin, and leptin plays a crucial role in food intake. In this study, we investigated the therapeutic effects of one of the traditional herbal medicines, Sipjeondaebo-tang (Juzen-taiho-to in Japanese; SJDBT), on cancer anorexia and cachexia in a fundamental mouse cancer anorexia/cachexia model, CT-26 tumor-bearing mice. SJDBT was more significantly effective in a treatment model where it was treated after anorexia and cachexia than in a prevention model where it was treated before anorexia and cachexia on the basis of parameters such as weights of muscles and whole body and food intakes. Moreover, SJDBT inhibited a production of IL-6, MCP-1, PYY, and GLP-1 and ameliorated cancer-induced anemia. Therefore, our in vivo studies provide evidence on the role of SJDBT in cancer-associated anorexia and cachexia, thereby suggesting that SJDBT may be useful for treating cancerassociated anorexia and cachexia.

\section{Introduction}

Cancer anorexia and cachexia correlate with a high mortality rate, poor response to chemotherapy, poor performance status, and poor quality of life (QOL), particularly in physical, psychological, and social functions in cancer patients $[1,2]$. Anorexia, which is characterized by the loss of desire to eat or loss of appetite, causes weight loss and malnutrition in cancer patients $[3,4]$. Cachexia is a multifactorial condition described by muscle loss, which is in part associated with loss of body weight, anorexia, asthenia, and anemia $[5,6]$. Cachexia occurs in about half of all cancer patients, and lung and upper gastrointestinal tract cancer patients have the highest frequency of cachexia, whereas patients with breast and lower gastrointestinal tract cancer have the lowest frequency of cachexia [7]. In addition, cachexia affects an ability of cancer patients to sustain chemotherapy or radiotherapy [8].
Therefore, it is important to manage anorexia and cachexia in cancer patients. However, current therapies for cancer patients with anorexia and cachexia are limited due to both poor efficacies and side effects of chemotherapeutics [9]. So, different therapeutic options are required to prevent cancer anorexia and cachexia.

Sipjeondaebo-tang (Juzen-taiho-to in Japanese and ShiQuan-Da-Bu-Tang in Chinese; SJDBT), commonly used traditional herbal medicines in Korea, China, and Japan [10], is composed of 10 species of herbs. SJDBT is prescribed for patients suffering from anemia, fatigue, anorexia, scaly skin, and dryness of the mouth [11-13]. In addition, SJDBT has been known to have anticancer effects [14-19]. Nevertheless, its effect on cancer cachexia is poorly understood. Here, we examined the effect of SJDBT on key parameters of cancer anorexia and cachexia and found that SJDBT ameliorated cancer anorexia and cachexia in vivo by altering body and 


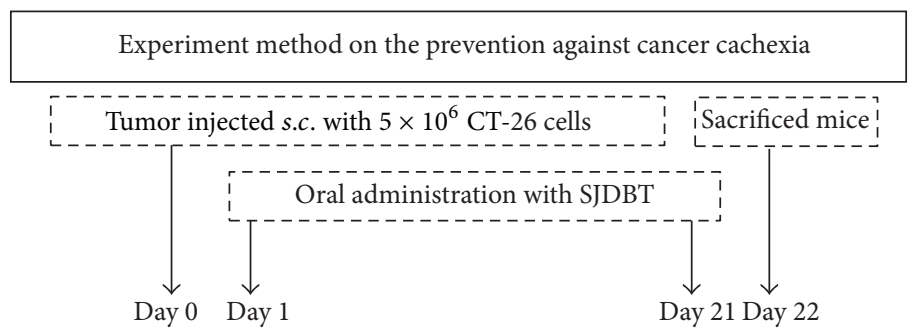

(a)

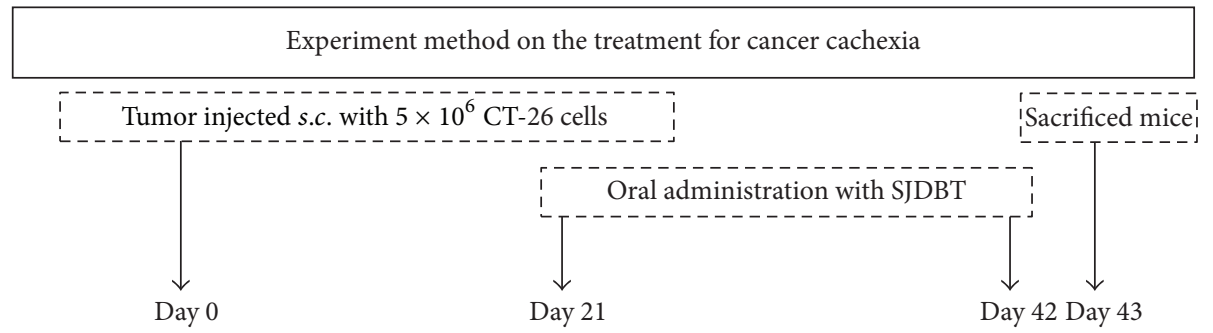

(b)

FIGURE 1: Schedules for prevention and therapy models of mouse cancer-induced cachexia. $5 \times 10^{6}$ CT-26 tumor cells were subcutaneously (s.c.) injected into the right flank of BALB/c mice. (a) Experiment method on the prevention: a day after tumor cell inoculation, three doses of SJDBT (L-SJDBT of $6.784 \mathrm{mg} / \mathrm{kg}$, M-SJDBT of $67.84 \mathrm{mg} / \mathrm{kg}$, and H-SJDBT of $678.4 \mathrm{mg} / \mathrm{kg}$ ) were p.o. administrated daily for 21 days. At 22 days after tumor cell injection, mice were sacrificed. (b) Experiment method on the therapy: 21 days after tumor cell inoculation (a day when cachexia was held), three different doses of SJDBT (L-SJDBT of $6.784 \mathrm{mg} / \mathrm{kg}, \mathrm{M}-\mathrm{SJDBT}$ of $67.84 \mathrm{mg} / \mathrm{kg}$, and H-SJDBT of $678.4 \mathrm{mg} / \mathrm{kg}$ ) were p.o. administrated daily for 21 days. At the end of experiments (42 days after tumor cell injection), mice were sacrificed.

muscle weights, food intakes, and levels of cytokines, hormones, RBC, Hb, and HCT in CT-26 tumor-bearing mice suffering from anorexia and cachexia, thereby suggesting that SJDBT may be useful for treating cancer anorexia and cachexia.

\section{Materials and Methods}

2.1. Preparation of SJDBT. SJDBT were prepared by and obtained from Hanpoong Pharmaceutical Company (Jeonju, Korea) following the good manufacturing practices (GMP) procedures. SJDBT is manufactured as dried powder of hot water extract obtained from 10 herbs $(320 \mathrm{~g}$ of Angelica gigas, $320 \mathrm{~g}$ of Astragalus membranaceus, $320 \mathrm{~g}$ of Atractylodes japonica, $320 \mathrm{~g}$ of Cinnamomum cassia, $320 \mathrm{~g}$ of Cnidium officinale, $160 \mathrm{~g}$ of Glycyrrhiza uralensis, $320 \mathrm{~g}$ of Paeonia lactiflora, $320 \mathrm{~g}$ of Panax ginseng, $320 \mathrm{~g}$ of Poria cocos, and $320 \mathrm{~g}$ of Rehmannia glutinosa; average yield $=28.85 \%$ ). The dried powders were lyophilized and then dissolved the three different doses (low dose: $6.784 \mathrm{mg} / \mathrm{kg}$, middle dose: $67.84 \mathrm{mg} / \mathrm{kg}$, and high dose: $678.4 \mathrm{mg} / \mathrm{kg}$ ) in distilled water.

2.2. Animal Study for Cancer Cachexia. Male BALB/c mice were purchased from Central Lab Animal Inc. (Seoul, Korea) at 6 weeks of age, and all mice were kept in pathogenfree environment. Mice were randomized into two groups (prevention or therapy model of cachexia). Each group was divided into subgroups (5 prevention groups: normal, control, low dose SJDBT (L-SJDBT of $6.784 \mathrm{mg} / \mathrm{kg}$ ), middle dose SJDBT (M-SJDBT of $67.84 \mathrm{mg} / \mathrm{kg}$ ), and high dose SJDBT (HSJDBT of $678.4 \mathrm{mg} / \mathrm{kg}) ; 6$ treatment groups: normal, control, L-SJDBT, M-SJDBT, H-SJDBT, and megestrol acetate- (MA-) treated). Animal studies were approved by the animal care center of Kyung-Hee University (KHUASP (SE)-12-048). The murine CT-26 tumor-bearing mouse was widely used for cancer cachexia model [20]. CT-26 colon carcinoma cell was obtained from the American Type Culture Collection (ATCC) (Manassas, VA, USA) and from Dr. Suk-Chan Lee (Department of Genetic Engineering, Sungkyunkwan University, Suwon, Korea). Cells were cultured in RPMI-1640 medium with $10 \%$ fetal bovine serum and $1 \%$ antibiotics. The schematic experimental procedure is described in Figure 1. For the prevention model of cancer-induced anorexia and cachexia, mice were injected s.c. with CT-26 cells $\left(5 \times 10^{6}\right)$. A day after tumor cell injection, three different doses of SJDBT (L-SJDBT, M-SJDBT, or H-SJDBT) were p.o. added daily for 21 days. For the treatment model of cancer-induced anorexia and cachexia, mice were injected s.c. with CT-26 cells $(5 \times$ $10^{6}$ ) and then three different doses of SJDBT (L-SJDBT, MSJDBT, or H-SJDBT) were p.o. added daily for 21 days at 3 weeks after tumor cell injection (Figure 6). MA (Santa Cruz Biotechnology, CA, USA) was used as a positive control for anorexic effect and dissolved in corn oil (100 mg/kg).

2.3. Measurement of Food Intakes and Weights of Whole Body and Muscles. Body weight and food intake were measured every day using an electronic scale. The measured quantity of food intake was divided by the number of mice to determine each intake per animal per day. At the time of sacrifice, the gastrocnemius muscles were dissected and weighted.

2.4. Measurement of Levels of Cytokines and Hormones and Blood Analysis. Whole blood samples were collected by cardiac puncture, and serum was obtained after being 


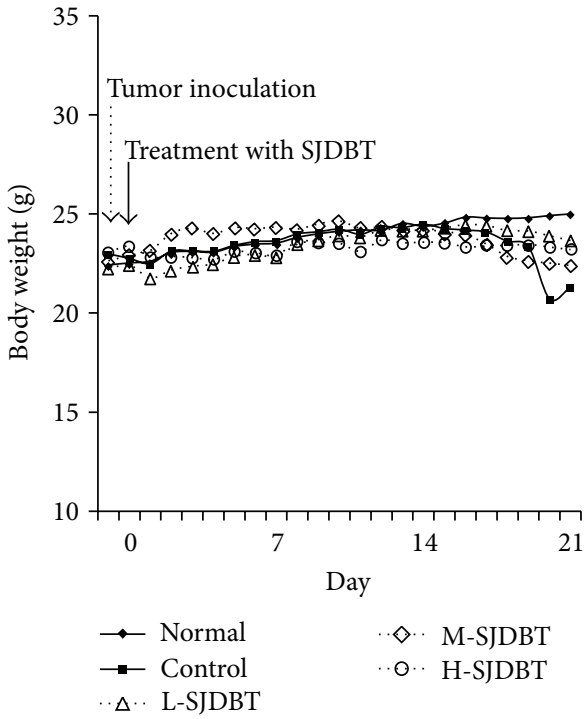

(a)

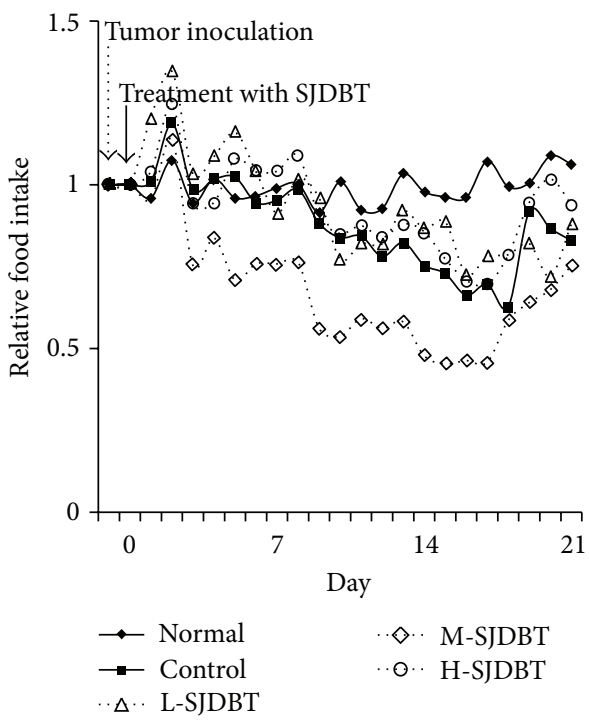

(c)

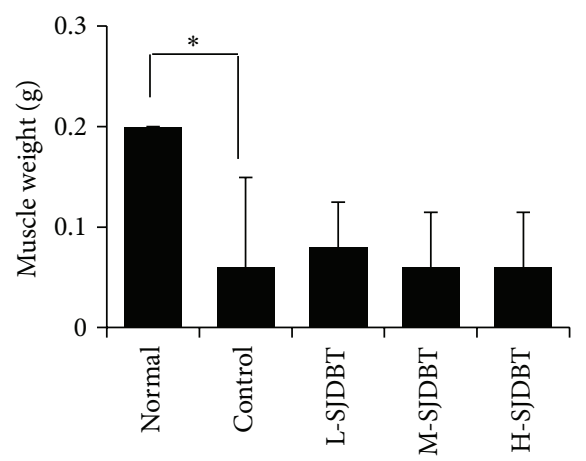

(e)

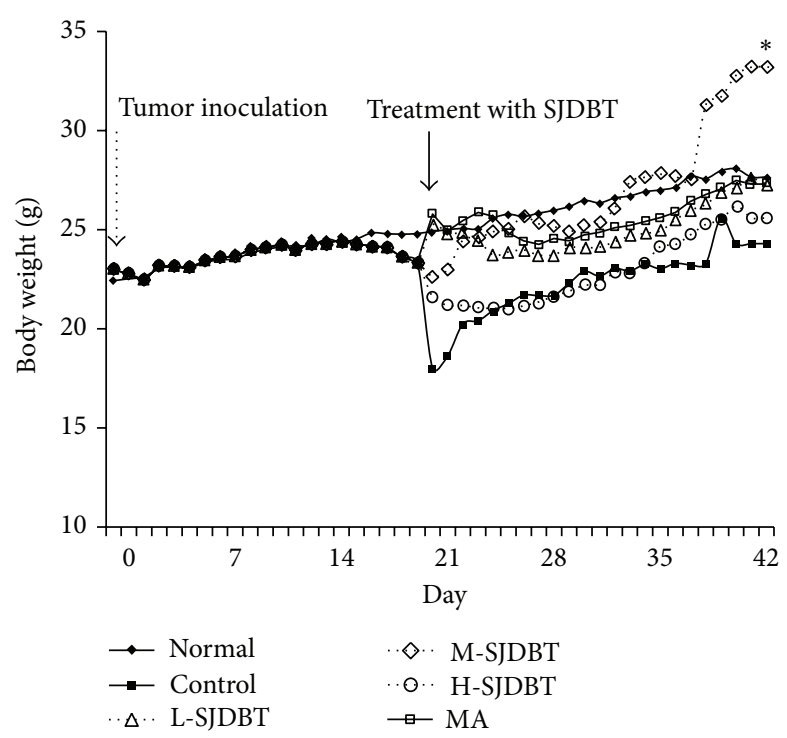

(b)

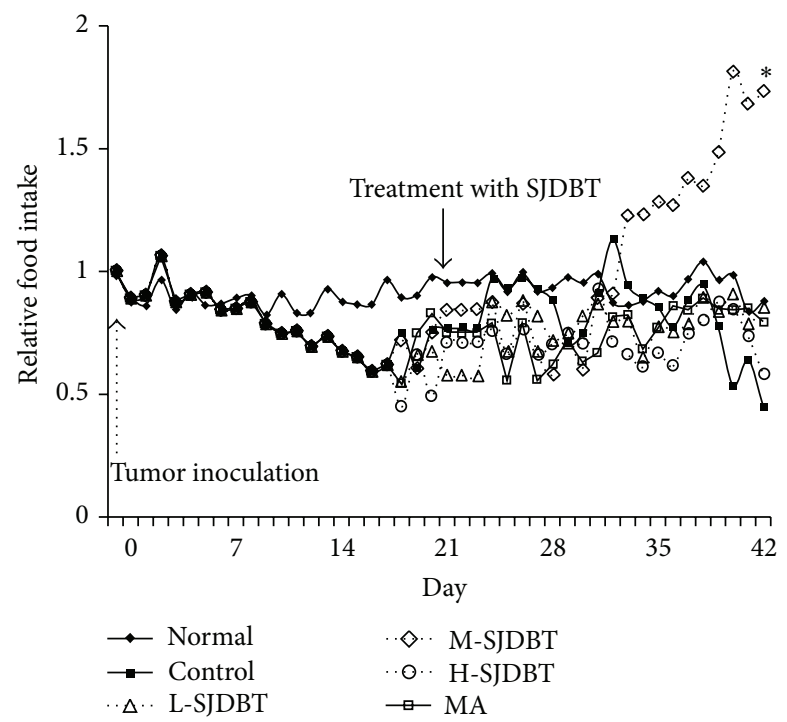

(d)

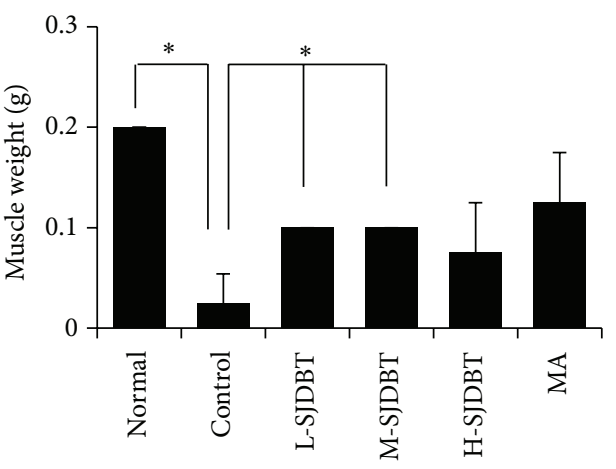

(f)

FIGURE 2: Effect of SJDBT on body weight and food intake in CT-26 tumor-bearing mice. ((a), (b)) Body weight of mice was measured every day at the same time. ((c), (d)) Food intake was measured every day at the same time. The measured quantity of food intake was divided by the number of total mice to determine each intake per animal a day. $\bullet$ : healthy normal mice $(n=5)$, $\mathbf{m}$ : untreated control tumor-bearing mice $(n=5), \triangle$ : low concentration $(6.784 \mathrm{mg} / \mathrm{kg})$ of SJDBT-treated tumor-bearing mice $(n=5), \diamond: \mathrm{middle} \mathrm{concentration}(67.84 \mathrm{mg} / \mathrm{kg})$ of SJDBT-treated tumor-bearing mice $(n=5)$, O: high concentration $(678.4 \mathrm{mg} / \mathrm{kg})$ of SJDBT-treated tumor-bearing mice $(n=5)$, and $\square$ : megestrol acetate-treated tumor-bearing mice $(n=5) .{ }^{*} P<0.05$. 


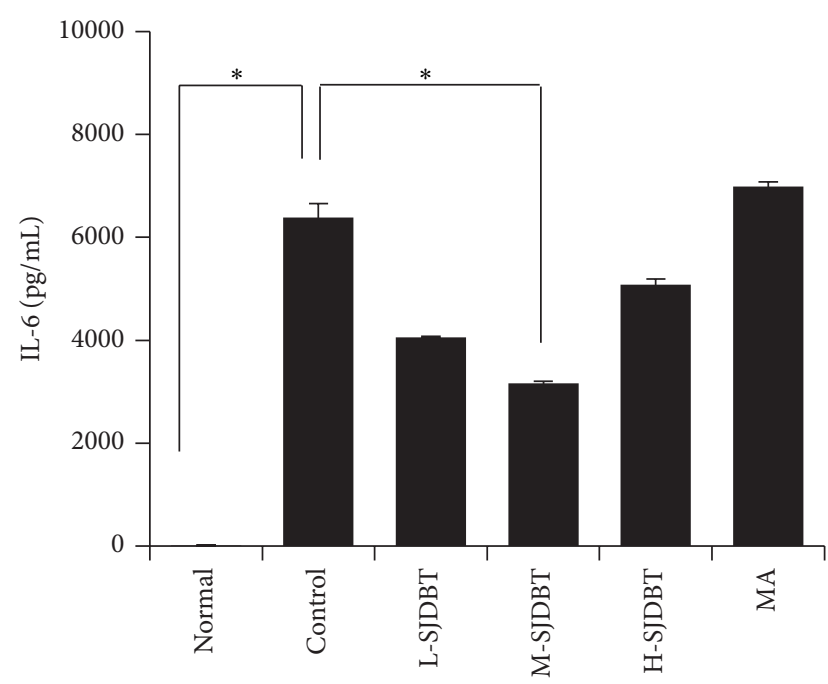

(a)

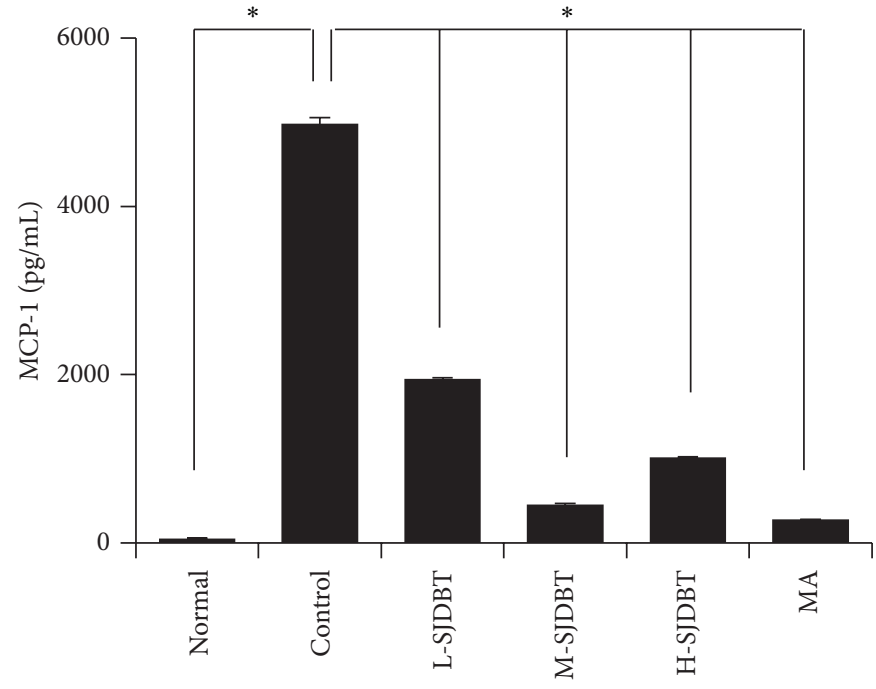

(b)

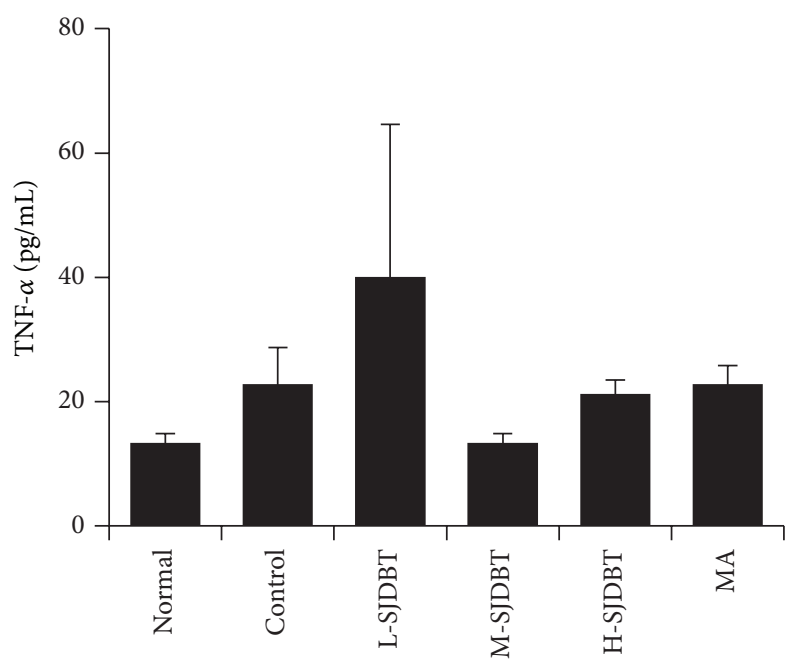

(c)

FIGURE 3: Effect of SJDBT on serums IL-6, MCP-1, and TNF- $\alpha$ levels in CT-26 tumor-bearing mice. ((a), (b)) 21 days after tumor cell injection, SJDBT were p.o. administrated every day until 42 days. At the end of experiments, mice were sacrificed. Blood samples were collected by cardiac puncture and serum samples were obtained blood sample after centrifuged. IL-6, MCP-1, and TNF- $\alpha$ level were measured using a Milliplex Mouse Metabolic Magnetic Bead Panel MMHMAG-44K-14. Experiments were performed in duplicate. Bars indicate means and standard deviations. ${ }^{*} P<0.05$.

centrifuged from the whole blood. Cytokines and hormones level were measured using a Milliplex Mouse Metabolic Magnetic Bead Panel MMHMAG-44K-14 (Millipore, MO, USA) in a Luminex 200. Standards were plotted and concentrations were determined using Milliplex Analyst software version 5.1. The blood samples were placed in Vacutainer TM tubes containing EDTA (BD Science, NJ, USA). Blood analysis was performed using the HEMAVET 950 hematology analyzer (Drew Scientific, Inc., Oxford, CT) in accordance with manufacturer's recommendation.

2.5. Statistics. Data were presented as the mean and standard deviation. $P$ values less than 0.05 in two-tailed student's $t$-test or one-way ANOVA were considered statistically significant.

\section{Results}

3.1. SJDBT Improves Cancer-Induced Weight Loss and Anorexia in CT-26 Tumor-Bearing Mice. To examine whether SJDBT prevents cancer-induced cachexia or treats cancerinduced cachexia, we divided into two groups (Figure 1). A day when CT-26 tumor cells were injected into mice was designated as day 0 . We found that control groups in each experimental set compared to the normal group showed reductions of body weights by approximately $14.8 \%$ and $36.8 \%$, respectively, at 21 days after tumor cell inoculations (Figures 2(a) and 2(b)), confirming that the injection of CT26 tumor cells resulted in the loss of body weight. SJDBT was treated for 21 days prior to cancer-induced anorexia and cachexia in the prevention model and treated for 21 days after 


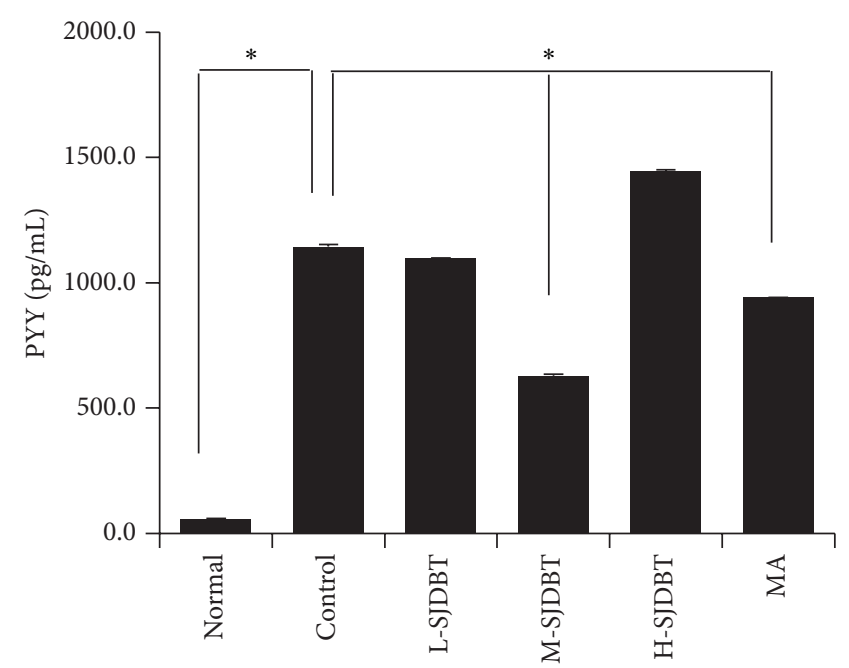

(a)

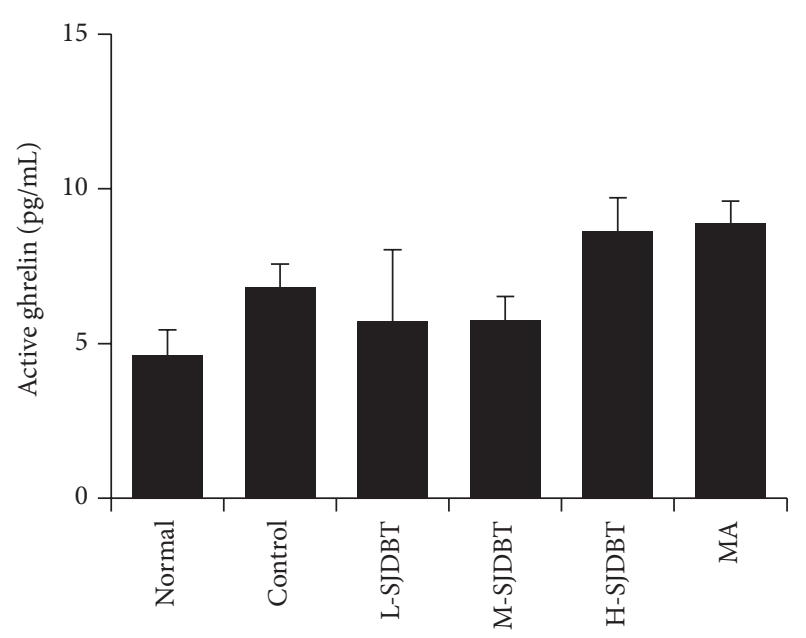

(c)

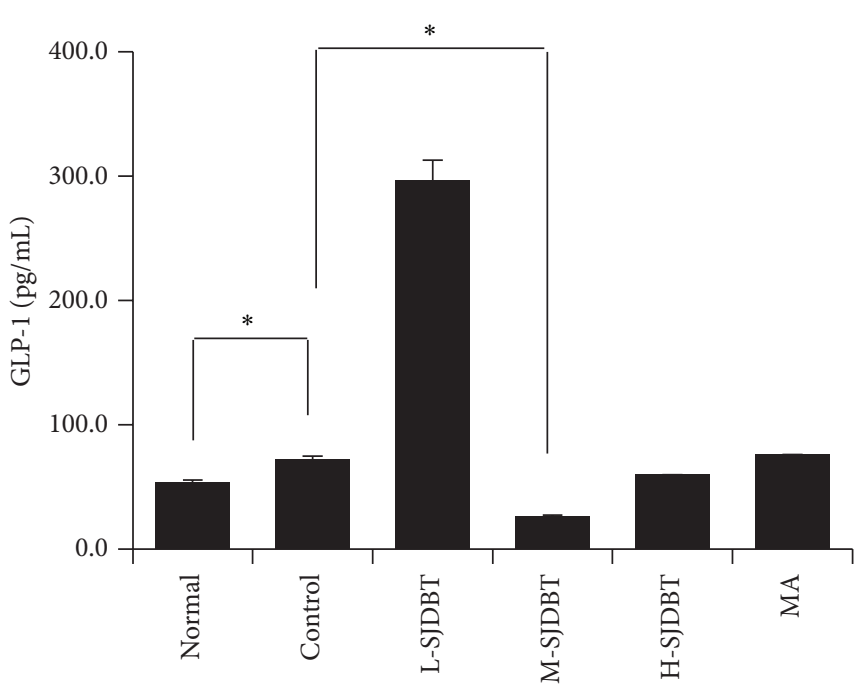

(b)

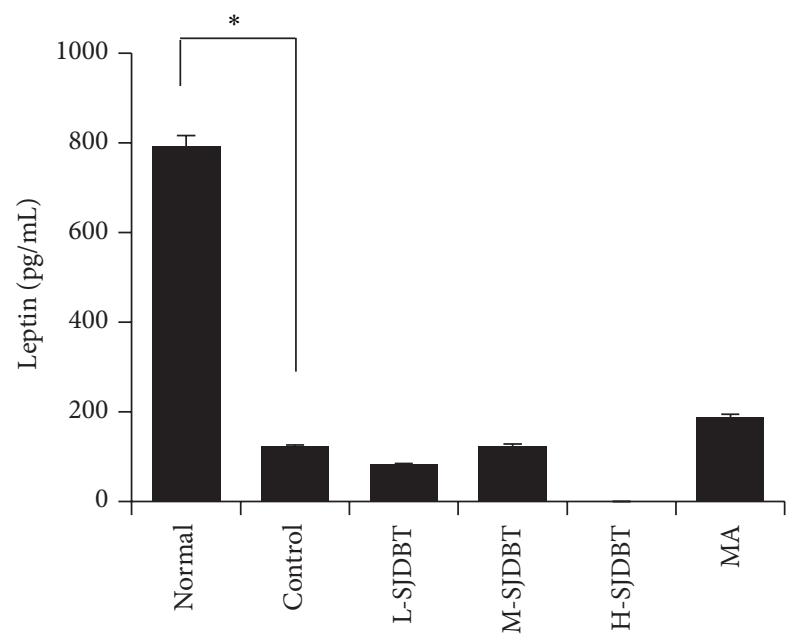

(d)

Figure 4: Effect of SJDBT on serums GLP-1, PYY, ghrelin, and leptin level in CT-26 tumor-bearing mice. ((a), (b)) 21 days after tumor cell injection, SJDBT were p.o. administrated for 21 days. At the end of experiments, mice were sacrificed. Blood samples were collected by cardiac puncture and serum samples were obtained blood sample after centrifuged. GLP-1, PYY, ghrelin, and leptin level were measured using a Milliplex Mouse Metabolic Magnetic Bead Panel MMHMAG-44K-14. Experiments were performed in duplicate. Bars indicate means and standard deviations. ${ }^{*} P<0.05$.

cancer-induced anorexia and cachexia in a therapy model. As shown in Figure 2(a), we found that L-SJDBT and H-SJDBT compared to the control increased body weights slightly by approximately $11.1 \%$ and $8.9 \%$, respectively, while being not statistically significant. Otherwise, when SJDBT were administered into mice after cancer-induced weight loss, MSJDBT-treated mice compared to the control significantly increased the weight by approximately $36.6 \%$ (Figure 2(b)). Therefore, SJDBT appeared to treat tumor-induced loss of body weight. Next, we performed experiments to determine whether SJDBT improves the appetite in a model of either prevention or treatment. L-SJDBT and H-SJDBT, compared to the control, ameliorated cancer-induced anorexia by approximately $25.3 \%$ and $25.1 \%$, respectively, in the prevention model (Figure 2(c)). In addition, M-SJDBT compared to the control significantly increased food intake in the therapy model (Figure 2(d)). The control group compared to the normal decreased muscle weight by approximately $70 \%$ at 22 days after tumor cell injection and by approximately $87.5 \%$ at 43 days after tumor cell inoculation (Figures 2(e) and 2(f)). Both L-SJDBT and M-SJDBT prevented tumor-induced loss of muscle weight in the therapy model, since muscle weights of tumor-bearing mice treated with each of them were higher than those of tumor-bearing mice untreated by approximately 4 -fold (Figure 2(f)). However, those were not effective in the prevention model (Figure 2(e)). Those results indicate that SJDBT may be effective for treating anorexia and for attenuating cachectic phenomenon, loss of muscle weight. Furthermore, our data showed that M-SJDBT was much more effective than MA in the treatment of cancerinduced reduction of food intake, while MA has been used to treat anorexia. 


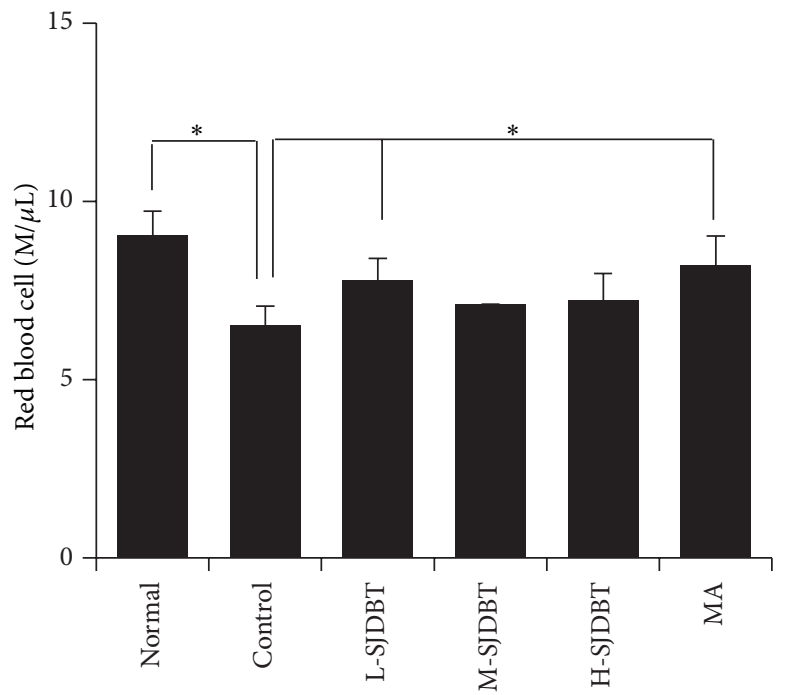

(a)

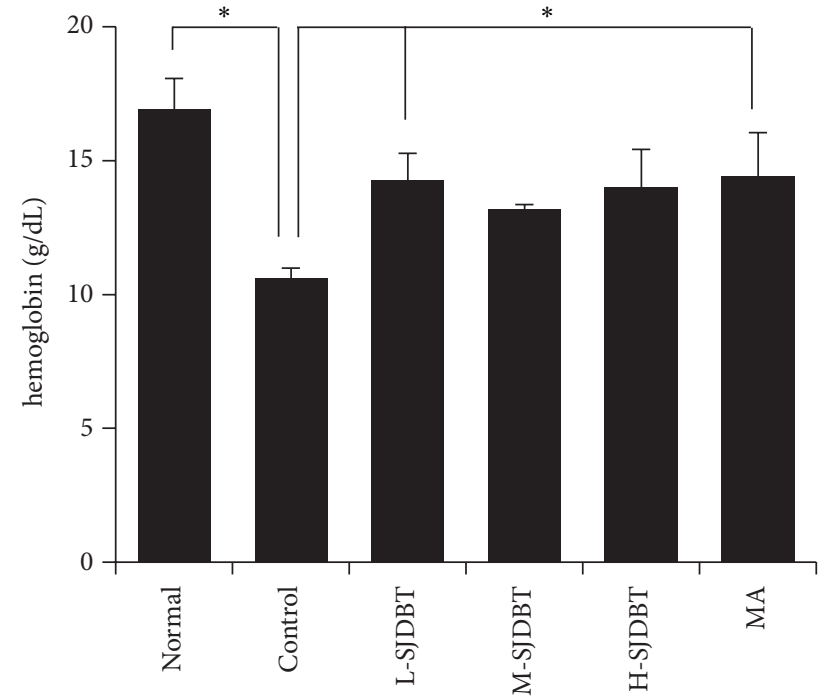

(b)

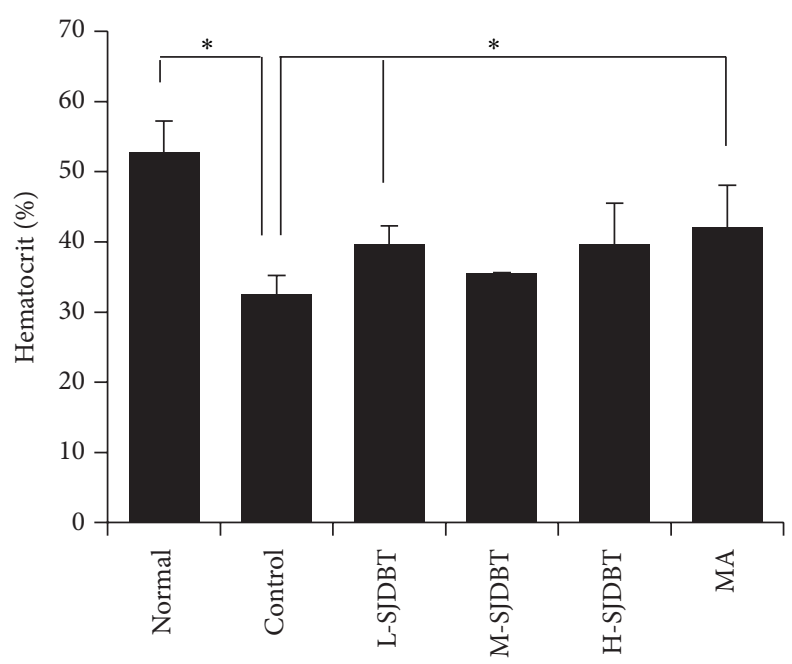

(c)

Figure 5: Blood analysis. ((a), (b), and (c)) 21 days after tumor cell injection, SJDBT were p.o. administrated for 21 days. At the end of experiments, mice were sacrificed. Whole blood samples were collected by cardiac puncture. The blood was placed in Vacutainer TM tubes containing EDTA (BD science, NJ, USA). Blood analysis was performed using the HEMAVET 950 hematology analyzer (Drew Scientific, Inc., Oxford, CT, USA) in accordance with manufacturer's recommendation.

\subsection{SJDBT Suppressed IL-6 and MCP-1 but Not TNF- $\alpha$ in} the Therapy Model. As proinflammatory cytokines such as interleukin-6 (IL-6), monocyte chemoattractant protein-1 (MCP-1), and tumor necrosis factor- $\alpha$ (TNF- $\alpha$ ) derived from tumor cells were associated with cancer-related anorexia and cachexia [21, 22], we next examined whether SJDBT affects serum levels of IL-6, MCP-1, and TNF- $\alpha$. Levels of IL- 6 and MCP-1 significantly increased in the control compared to the normal by approximately 480-fold and 91-fold, respectively (Figures 3(a) and 3(b)). In addition, M-SJDBT significantly inhibited cancer-induced induction of IL- 6 and MCP-1 by approximately $50.5 \%$ and $90.8 \%$, respectively (Figures 3(a) and 3(b)). Furthermore, MCP-1 level was uniquely altered in all tested doses of SJDBT. Whereas the serum level of TNF- $\alpha$ increased slightly in the control compared to the normal by approximately 1.7 -fold, M-SJDBT compared to the control reduced TNF- $\alpha$ level by approximately $41.4 \%$ while it was not statistically significant (Figure 3(c)). These results suggest that $\mathrm{M}$-SJDBT may ameliorate cancer-induced anorexia and cachexia by altering levels of cytokines such as IL-6 and MCP-1.

\subsection{Effects of SJDBT on Levels of Gut Hormones and Leptin in} the Therapy Model. As anorexia involves appetite-regulating hormones such as gut hormones (GLP-1, PYY, and ghrelin) and leptin $[23,24]$, we further examined whether SJDBT affects their levels in serum. Levels of GLP-1 and PYY significantly increased in the control compared to normal by approximately 1.3-fold and 20-fold, respectively (Figures 4(a) and 4(b)). M-SJDBT significantly inhibited cancer-induced induction of both GLP-1 and PYY by approximately $63.2 \%$ and $44.9 \%$, respectively (Figures $4(\mathrm{a})$ and $4(\mathrm{~b})$ ). However, 


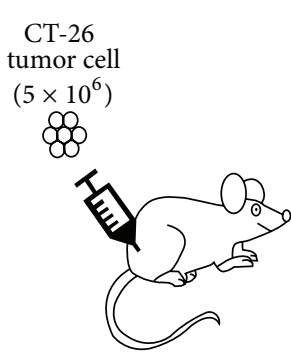

Injection in the flank with CT-26 tumor cell

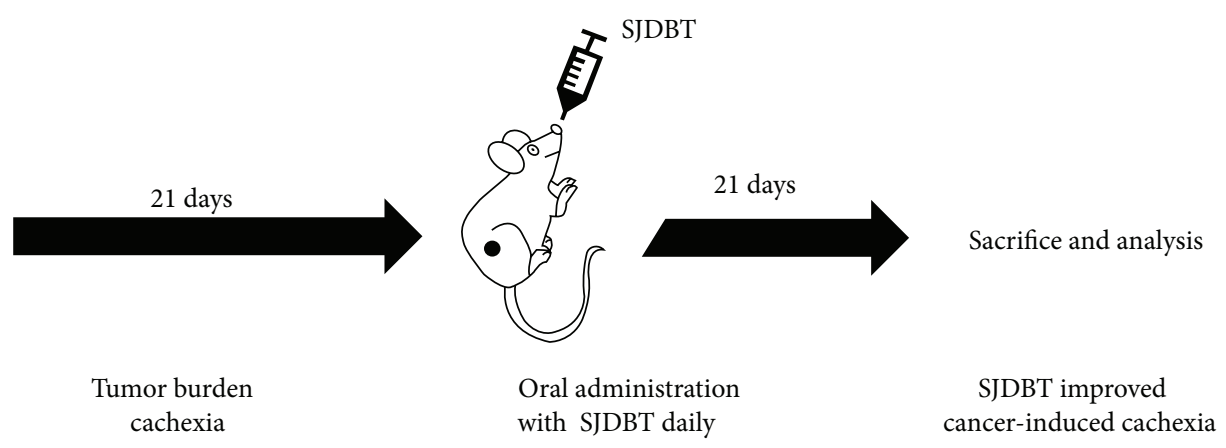

Loss of body weight

Loss of food intake

Loss of muscle weight

Change of cytokines level

Change of hormones level

\author{
Healthy normal group \\ Control tumor-bearing group \\ SJDBT-treated group \\ - L-SJDBT (6.784 mg/kg) \\ - M-SJDBT $(67.84 \mathrm{mg} / \mathrm{kg})$ \\ - H-SJDBT ( $678.4 \mathrm{mg} / \mathrm{kg}$ ) \\ MA-treated group
}

\author{
Body weight $\uparrow$ \\ Food intake $\uparrow$ \\ IL-6 $\uparrow$ \\ MCP-1 $\uparrow$ \\ $\mathrm{PYY} \downarrow$ \\ GLP-1 $\downarrow$ \\ $\mathrm{RBC} \uparrow, \mathrm{Hb} \uparrow$, and $\mathrm{HCT} \uparrow$
}

Figure 6: Schematic illustration. To set up the tumor burden cachexia mice model, mice were injected s.c. with CT-26 tumor cells. 21 days after tumor cell injection, three doses of SJDBT (L-SJDBT, M-SJDBT, and H-SJDBT) and MA were p.o. added daily. After treatment with indications for 21 days, mice were sacrificed and blood samples were analyzed for blood analysis and cytokines and hormones level in serum. SJDBT improved cancer cachexia in mice and inhibited the production of IL-6, MCP-1, PYY, and GLP-1. Therefore, we conclude that SJDBT improves cancer-induced cachexia including weight loss, anorexia, muscle wasting, anemia, and dysregulation of cytokines and hormones.

levels of ghrelin and leptin were not altered by M-SJDBT. Those results suggest that M-SJDBT regulation of GLP-1 and PYY may affect cancer-associated anorexia and cachexia.

\subsection{SJDBT Improves Cancer-Induced Anemia in CT-26} Tumor-Bearing Mice. Because cancer-induced anorexia and cachexia are a multifactorial syndrome including anemia [25], we measured levels of red blood cells in blood samples using HEMAVET 950 hematology analyzer. The control compared to the normal accrued anemia, which was measured by numbers of red blood cells (RBC; normal mice versus control mice; $9.04 \pm 0.68 \mathrm{M} / \mu \mathrm{L}$ versus $6.53 \pm 0.44 \mathrm{M} / \mu \mathrm{L} ; P=$ 0.02 ), hemoglobins ( $\mathrm{Hb}$; normal mice versus control mice; $16.91 \pm 1.15 \mathrm{~g} / \mathrm{dL}$ versus $10.6 \pm 0.38 \mathrm{M} / \mu \mathrm{L} ; P=0.0001)$, and hematocrits (HCT; percentage of red blood cells in whole blood; normal mice versus control mice; $52.9 \pm 4.32 \%$ versus $32.53 \pm 2.68 \% ; P=0.03)$. L-SJDBT compared to the control significantly increased values of RBC, $\mathrm{Hb}$, and HCT by approximately $18 \%, 34.7 \%$, and $22 \%$, respectively (Figures 5(a), 5(b), and 5(c)). In addition, MA similarly affected those values, indicating that the treatment of anorexia might be linked to alterations of those values. While M-SJDBT compared to the control increased values of $\mathrm{RBC}, \mathrm{Hb}$, and HCT by approximately $7.6 \%, 24.5 \%$, and $9.4 \%$, respectively, those were not statistically significant. Therefore, those results indicate that L-SJDBT may be a good remedy for cancermediated anemia.

\section{Discussion}

As herbal medicine therapy has been known to be beneficial with high efficacy and safety, market of herbal medicine therapy is growing in Korea, China, and Japan as well as in the United States [26]. Especially, herbal medicines are used for clinical trial and therapy in cancer patients [27, 28]. However, biomedical scientists have limitations to use the herbal medicines due to the lack of evidence even in lab-based experimental studies [28]. For example, SJDBT is widely used for cancer patients suffering from symptoms such as loss of appetite, fatigue, and anemia in Korea, China, and Japan $[10,12,13,29]$. However, its effect on the loss of either weight or food intake is still unknown. In this present study, we showed SJDBT effect on cancer anorexia and cachexia.

Cancer-induced anorexia and cachexia involve proinflammatory cytokines such as IL-6, MCP-1, and TNF- $\alpha$ [21, 22]. Furthermore, it has been suggested that MCP-1 rather than TNF- $\alpha$ is more important for cancer cachexia $[22,30$, 31]. Circulating level of IL-6 is known to be important for keeping body weight and for survival in cancer patients [3234]. In our study, SJDBT reduced IL- 6 but increased MCP1 , while it did not affect TNF- $\alpha$. Thus, it is plausible that SJDBT may modulate effects of cytokines on cancer-induced anorexia and cachexia. Meanwhile, GLP-1, PYY, ghrelin, and leptin are known as readouts for anorexia/cachexia [35]. SJDBT significantly suppressed GLP-1 and PYY levels, whereas it did not affect ghrelin and leptin. In sum, our data suggest that SJDBT ameliorates cancer-associated anorexia/cachexia by regulating cytokines (IL-6 and MCP-1) and hormones (GLP-1 and PYY). Anemia is tone of common features of cancer cachexia $[6,8,36]$. Especially, anemia is linked to the fatigue and QOL in cancer patients [36]. In addition, $\mathrm{Hb}$ level is supposed to be related to QOL [37]. SJDBT increased values of RBC, Hb, and HCT, which further indicates that SJDBT is beneficial for treating cancer anorexia/cachexia. 
Cancer-associated anorexia is related to central mechanisms governing food intake [38]. Food intake is controlled by neuroendocrine paths through central nervous system (CNS) [39]. Short-term reaction for food intake is mediated by peptides produced by enteroendocrine cells in the gastrointestinal tract [39]. Incretin hormones such as GLP1 mediate a response of the pancreas to nutrients, resulting in the reduction of food intake. Likewise, ghrelin is secreted from the stomach and promotes appetite. Leptin mediates long-term reaction for food intake. It is produced mainly from the adipose and stimulates food intake through CNS [40]. Furthermore, cancer-associated anorexia is caused by chronic stimulations via cytokines released from cancer cells or from host cells responding to cancer cells [41]. Cytokines have been known to interrupt with appetite-stimulating signaling [42]. Furthermore, cytokines impair muscle and fat metabolisms, which is tightly linked to cancer-associated anorexia $[42,43]$. While cytokines such as TNF- $\alpha$ and IL-6 have been known to mediate cancer cachexia [42], SJDBT reduced IL- 6 level without altering TNF- $\alpha$. IL- 6 is known to cause the loss of lean body weight in CT-26 tumor-bearing cachectic mice by inducing proteolytic pathways [44]. In addition, MCP-1, the circulating level of which was altered by SJDBT, has been known to regulate leptin level in the adipose and to mediate cachexia [22, 45]. Therefore, it is plausible that SJDBT may target cytokine production in cancer cells, which may result in modulations of hormone levels. However, we could not exclude possibilities that SJDBT may target multiple sources including cancer cells, cancerassociated immune cells, adipocytes, and hypothalamic neurons. Recent studies have revealed functional relationships between cytokines (IL-6 and MCP-1) and hormones (GLP-1 and PYY) [46-51]. Thus, it remains to be deciphered molecular and cellular mechanisms of SJDBT to ameliorate cancerassociated anorexia and cachexia.

\section{Conclusion}

Our study demonstrates that the SJDBT ameliorates cancerinduced anorexia and cachexia in CT-26 tumor-bearing mouse model by altering the production of IL-6, MCP-1, PYY, and GLP-1. Our in vivo studies first provide evidence on the role of SJDBT in cancer-associated anorexia/cachexia, which suggests that SJDBT may be useful for patients with cancerassociated anorexia/cachexia.

\section{Conflict of Interests}

The authors declare that they have no conflict of interests.

\section{Author's Contribution}

Youn Kyung Choi, Sang-Mi Woo, and Yee Jin Yun carried out the experiment. Youn Kyung Choi, Ki Yong Jung, and Sang-Mi Woo analyzed data and wrote the paper. Chan-Yong Jun, Jong Hyeong Park, and Yong Cheol Shin assisted in data analyses. Sung-Gook Cho designed experimental concept and revised the paper. Seong-Gyu Ko designed concepts and supervised the study. Youn Kyung Choi, Ki Yong Jung, and Sang-Mi Woo equally contributed to this work.

\section{Acknowledgments}

The authors thank Dr. Suk-Chan Lee (Department of Genetic Engineering, Sungkyunkwan University, Suwon, Korea) for providing CT-26 cell line. This research was supported by a grant from Korean Medicine R\&D Project of the Ministry of Health and Welfare (B120014).

\section{References}

[1] W. D. Dewys, C. Begg, and P. T. Lavin, "Prognostic effect of weight loss prior to chemotherapy in cancer patients," The American Journal of Medicine, vol. 69, no. 4, pp. 491-497, 1980.

[2] J. K. Brown, "A systematic review of the evidence on symptom management of cancer-related anorexia and cachexia," Oncology Nursing Forum, vol. 29, no. 3, pp. 517-532, 2002.

[3] K. C. Fearon, A. C. Voss, and D. S. Hustead, "Definition of cancer cachexia: effect of weight loss, reduced food intake, and systemic inflammation on functional status and prognosis," The American Journal of Clinical Nutrition, vol. 83, no. 6, pp. 13451350, 2006.

[4] E. J. B. Ramos, S. Suzuki, D. Marks, A. Inui, A. Asakawa, and M. M. Meguid, "Cancer anorexia-cachexia syndrome: cytokines and neuropeptides," Current Opinion in Clinical Nutrition and Metabolic Care, vol. 7, no. 4, pp. 427-434, 2004.

[5] J. N. Gordon, S. R. Green, and P. M. Goggin, "Cancer cachexia," Monthly Journal of the Association of Physicians, vol. 98, no. 11, pp. 779-788, 2005.

[6] M. J. Tisdale, "Cachexia in cancer patients," Nature Reviews Cancer, vol. 2, no. 11, pp. 862-871, 2002.

[7] K. C. H. Fearon and A. G. W. Moses, "Cancer cachexia," International Journal of Cardiology, vol. 85, no. 1, pp. 73-81, 2002.

[8] A. Theologides, "Cancer cachexia," Cancer, vol. 43, supplement 5, pp. 2004-2012, 1979.

[9] M. Muscaritoli, M. Bossola, Z. Aversa, R. Bellantone, and F. Rossi Fanelli, "Prevention and treatment of cancer cachexia: new insights into an old problem," European Journal of Cancer, vol. 42, no. 1, pp. 31-41, 2006.

[10] K. Niwa, M. Hashimoto, S. Morishita et al., "Preventive effects of Juzen-taiho-to on N-methyl-N-nitrosourea and estradiol-17 $\beta$ induced endometrial carcinogenesis in mice," Carcinogenesis, vol. 22, no. 4, pp. 587-591, 2001.

[11] A. F. Sawalha, W. M. Sweileh, S. H. Zyoud, and S. W. Jabi, "Selftherapy practices among university students in Palestine: focus on herbal remedies," Complementary Therapies in Medicine, vol. 16, no. 6, pp. 343-349, 2008.

[12] T. Matsumoto, M. H. Sakurai, H. Kiyohara, and H. Yamada, "Orally administered decoction of Kampo (Japanese herbal) medicine, "Juzen-Taiho-To" modulates cytokine secretion and induces NKT cells in mouse liver," Immunopharmacology, vol. 46, no. 2, pp. 149-161, 2000.

[13] I. Saiki, "A Kampo medicine "Juzen-taiho-to"-prevention of malignant progression and metastasis of tumor cells and the mechanism of action," Biological and Pharmaceutical Bulletin, vol. 23, no. 6, pp. 677-688, 2000.

[14] M. Utsuyama, H. Seidlar, M. Kitagawa, and K. Hirokawa, "Immunological restoration and anti-tumor effect by Japanese herbal medicine in aged mice," Mechanisms of Ageing and Development, vol. 122, no. 3, pp. 341-352, 2001.

[15] R. Haranaka, R. Hasegawa, S. Nakagawa, A. Sakurai, N. Satomi, and K. Haranaka, "Antitumor activity of combination therapy 
with traditional Chinese medicine and OK432 or MMC," Journal of Biological Response Modifiers, vol. 7, no. 1, pp. 77-90, 1988.

[16] K. Sugiyama, H. Ueda, Y. Ichio, and M. Yokota, "Improvement of cisplatin toxicity and lethality by Juzen-taiho-to in mice," Biological and Pharmaceutical Bulletin, vol. 18, no. 1, pp. 53-58, 1995.

[17] Y. Onishi, T. Yamaura, K. Tauchi et al., "Expression of the antimetastatic effect induced by Juzen-taiho-to is based on the content of Shimotsu-to constituents," Biological and Pharmaceutical Bulletin, vol. 21, no. 7, pp. 761-765, 1998.

[18] Y. Ohnishi, H. Fujii, F. Kimura et al., "Inhibitory effect of a traditional Chinese medicine, Juzen-taiho-to, on progressive growth of weakly malignant clone cells derived from murine fibrosarcoma," Japanese Journal of Cancer Research, vol. 87, no. 10, pp. 1039-1044, 1996.

[19] Y. Ohnishi, H. Fujii, Y. Hayakawa et al., "Oral administration of a Kampo (Japanese herbal) medicine Juzen-taiho-to inhibits liver metastasis of colon 26-L5 carcinoma cells," Japanese Journal of Cancer Research, vol. 89, no. 2, pp. 206-213, 1998.

[20] P. Aulino, E. Berardi, V. M. Cardillo et al., "Molecular, cellular and physiological characterization of the cancer cachexiainducing C26 colon carcinoma in mouse," BMC Cancer, vol. 10, article 363, 2010.

[21] M. J. Tisdale, "Mechanisms of cancer cachexia," Physiological Reviews, vol. 89, no. 2, pp. 381-410, 2009.

[22] S. Michalak, M. Wender, and G. Michałowska-Wender, "Cachexia-induced cerebellar degeneration: involvement of serum TNF and MCP-1 in the course of experimental neoplastic disease," Acta Neurobiologiae Experimentalis, vol. 66, no. 2, pp. 113-122, 2006.

[23] P. J. Havel, "Peripheral signals conveying metabolic information to the brain: short-term and long-term regulation of food intake and energy homeostasis," Experimental Biology and Medicine, vol. 226, no. 11, pp. 963-977, 2001.

[24] C. W. Le Roux, S. J. B. Aylwin, R. L. Batterham et al., "Gut hormone profiles following bariatric surgery favor an anorectic state, facilitate weight loss, and improve metabolic parameters," Annals of Surgery, vol. 243, no. 1, pp. 108-114, 2006.

[25] R. Dhanapal, T. R. Saraswathi, and N. Govind Rajkumar, "Cancer cachexia," Journal of Oral and Maxillofacial Pathology, vol. 15, no. 3, pp. 257-260, 2011.

[26] M. K. Bedi and P. D. Shenefelt, "Herbal therapy in dermatology," Archives of Dermatology, vol. 138, no. 2, pp. 232-242, 2002.

[27] O. Olaku and J. D. White, "Herbal therapy use by cancer patients: a literature review on case reports," European Journal of Cancer, vol. 47, no. 4, pp. 508-514, 2011.

[28] S. Y. Yin, W. C. Wei, F. Y. Jian, and N. S. Yang, "Therapeutic applications of herbal medicines for cancer patients," Evidence-Based Complementary and Alternative Medicine, vol. 2013, Article ID 302426, 15 pages, 2013.

[29] H. Hisha, H. Yamada, M. H. Sakurai et al., "Isolation and identification of hematopoietic stem cell-stimulating substances from Kampo (Japanese herbal) medicine, Juzen-taiho-to," Blood, vol. 90, no. 3, pp. 1022-1030, 1997.

[30] G. Mantovani, A. Macciò, C. Madeddu et al., "Serum values of proinflammatory cytokines are inversely correlated with serum leptin levels in patients with advanced stage cancer at different sites," Journal of Molecular Medicine, vol. 79, no. 7, pp. 406-414, 2001.
[31] M. G. Catalano, N. Fortunati, K. Arena et al., "Selective up-regulation of tumor necrosis factor receptor I in tumor-bearing rats with cancer-related cachexia," International Journal of Oncology, vol. 23, no. 2, pp. 429-436, 2003.

[32] H. R. Scott, D. C. McMillan, A. Crilly, C. S. McArdle, and R. Milroy, "The relationship between weight loss and interleukin 6 in non-small-cell lung cancer," The British Journal of Cancer, vol. 73, no. 12, pp. 1560-1562, 1996.

[33] A. G. W. Moses, J. Maingay, K. Sangster, K. C. H. Fearon, and J. A. Ross, "Pro-inflammatory cytokine release by peripheral blood mononuclear cells from patients with advanced pancreatic cancer: relationship to acute phase response and survival," Oncology Reports, vol. 21, no. 4, pp. 1091-1095, 2009.

[34] D. S. Hong, L. S. Angelo, and R. Kurzrock, "Interleukin-6 and its receptor in cancer: implications for translational therapeutics," Cancer, vol. 110, no. 9, pp. 1911-1928, 2007.

[35] I. Wolf, S. Sadetzki, H. Kanely et al., "Adiponectin, ghrelin, and leptin in cancer cachexia in breast and colon cancer patients," Cancer, vol. 106, no. 4, pp. 966-973, 2006.

[36] M. Dicato, L. Plawny, and M. Diederich, "Anemia in cancer," Annals of Oncology, vol. 21, supplement 7, pp. viil67-viil72, 2010.

[37] J. Glaspy, L. Degos, M. Dicato, and G. D. Demetri, "Comparable efficacy of epoetin alfa for anemic cancer patients receiving platinum- and nonplatinum-based chemotherapy: a retrospective subanalysis of two large, community-based trials," Oncologist, vol. 7, no. 2, pp. 126-135, 2002.

[38] R. D. Cone, "Anatomy and regulation of the central melanocortin system," Nature Neuroscience, vol. 8, no. 5, pp. 571-578, 2005.

[39] E. T. Rolls, "Smell, taste, texture, and temperature multimodal representations in the brain, and their relevance to the control of appetite," Nutrition Reviews, vol. 62, no. 11, pp. S193-S204, 2004.

[40] A. Inui, "Feeding and body-weight regulation by hypothalamic neuropeptides-mediation of the actions of leptin," Trends in Neurosciences, vol. 22, no. 2, pp. 62-67, 1999.

[41] G. Sonti, S. E. Ilyin, and C. R. PlataSalaman, "Anorexia induced by cytokine interactions at pathophysiological concentrations," The American Journal of Physiology: Regulatory Integrative and Comparative Physiology, vol. 270, no. 6, part 2, pp. R1394-R1402, 1996.

[42] L. L. Moldawer, M. A. Rogy, and S. F. Lowry, “The role of cytokines in cancer cachexia," Journal of Parenteral and Enteral Nutrition, vol. 16, supplement 6, pp. 43S-49S, 1992.

[43] N. MacDonald, A. M. Easson, V. C. Mazurak, G. P. Dunn, and V. E. Baracos, "Understanding and managing cancer cachexia," Journal of the American College of Surgeons, vol. 197, no. 1, pp. 143-161, 2003.

[44] C. R. Plata-Salamán, S. E. Ilyin, and D. Gayle, "Brain cytokine mRNAs in anorectic rats bearing prostate adenocarcinoma tumor cells," The American Journal of Physiology: Regulatory Integrative and Comparative Physiology, vol. 275, no. 2, pp. R566-R573, 1998.

[45] C. C. Gerhardt, I. A. Romero, R. Cancello, L. Camoin, and A. D. Strosberg, "Chemokines control fat accumulation and leptin secretion by cultured human adipocytes," Molecular and Cellular Endocrinology, vol. 175, no. 1-2, pp. 81-92, 2001.

[46] Y. Ishibashi, Y. Nishino, T. Matsui, M. Takeuchi, and S. I. Yamagishi, "Glucagon-like peptide-1 suppresses advanced glycation end product-induced monocyte chemoattractant protein-1 expression in mesangial cells by reducing advanced glycation end product receptor level," Metabolism: Clinical and Experimental, vol. 60, no. 9, pp. 1271-1277, 2011. 
[47] Y. Kihira, M. Miyake, M. Hirata et al., "Deletion of hypoxia-inducible factor-lalpha in adipocytes enhances glucagon-like Peptide- 1 secretion and reduces adipose tissue inflammation," PLoS ONE, vol. 9, no. 4, Article ID e93856, 2014.

[48] R. Shirazi, V. Palsdottir, J. Collander et al., "Glucagon-like peptide 1 receptor induced suppression of food intake, and body weight is mediated by central IL-1 and IL-6," Proceedings of the National Academy of Sciences of the United States of America, vol. 110, no. 40, pp. 16199-16204, 2013.

[49] Y. S. Lee, M. S. Park, J. S. Choung et al., "Glucagon-like peptide-1 inhibits adipose tissue macrophage infiltration and inflammation in an obese mouse model of diabetes," Diabetologia, vol. 55, no. 9, pp. 2456-2468, 2012.

[50] H. Ellingsgaard, I. Hauselmann, B. Schuler et al., "Interleukin-6 enhances insulin secretion by increasing glucagon-like peptide1 secretion from L cells and alpha cells," Nature Medicine, vol. 17, no. 11, pp. 1481-1489, 2011.

[51] J. M. Garcia, M. Garcia-Touza, R. A. Hijazi et al., "Active ghrelin levels and active to total ghrelin ratio in cancer-induced cachexia," Journal of Clinical Endocrinology and Metabolism, vol. 90, no. 5, pp. 2920-2926, 2005. 


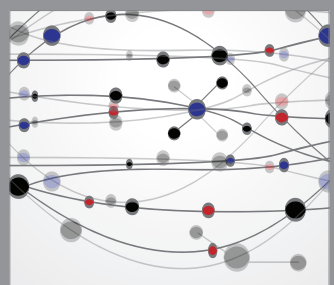

The Scientific World Journal
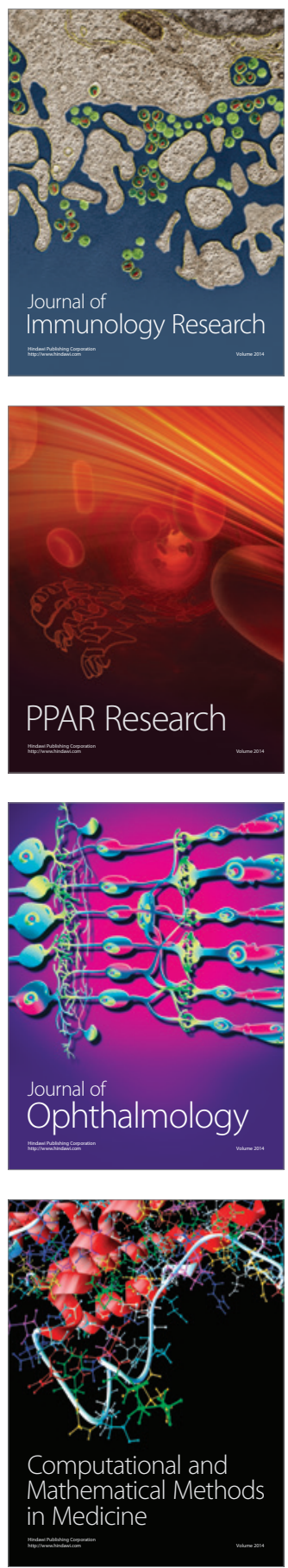

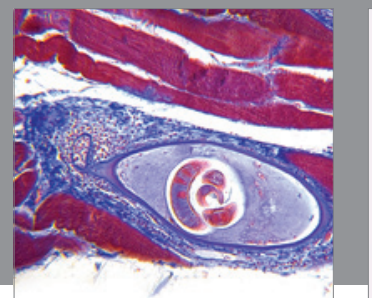

Gastroenterology

Research and Practice
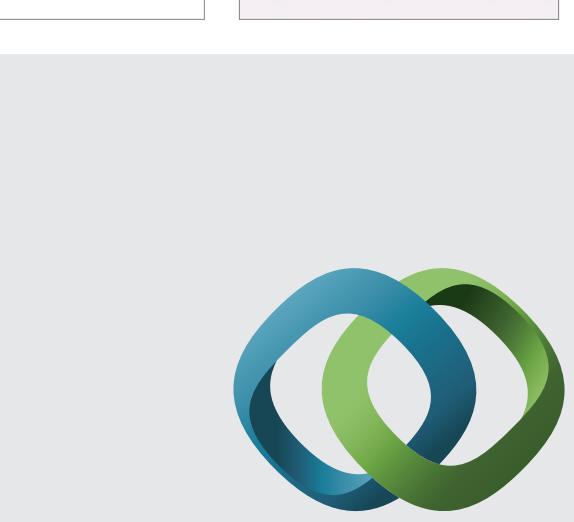

\section{Hindawi}

Submit your manuscripts at

http://www.hindawi.com
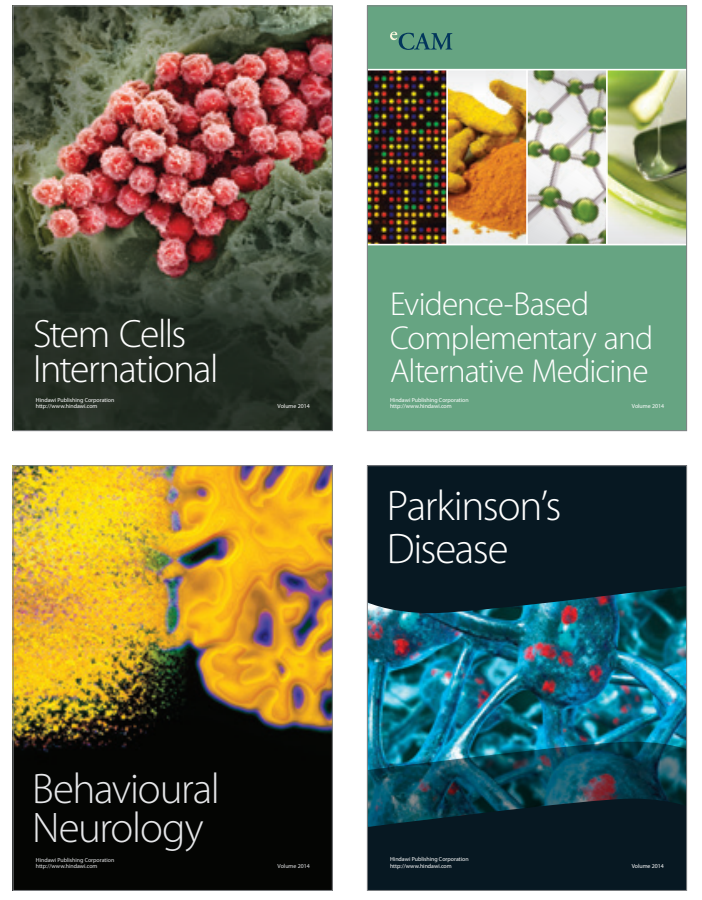
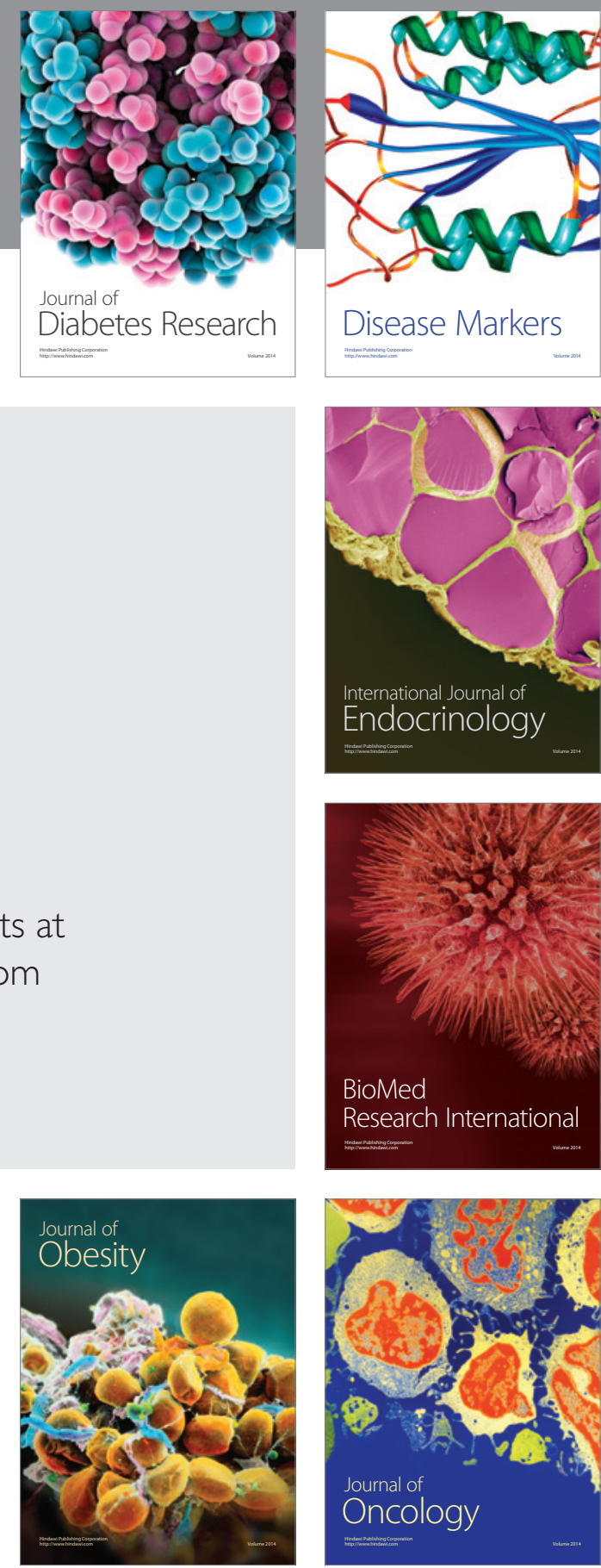

Disease Markers
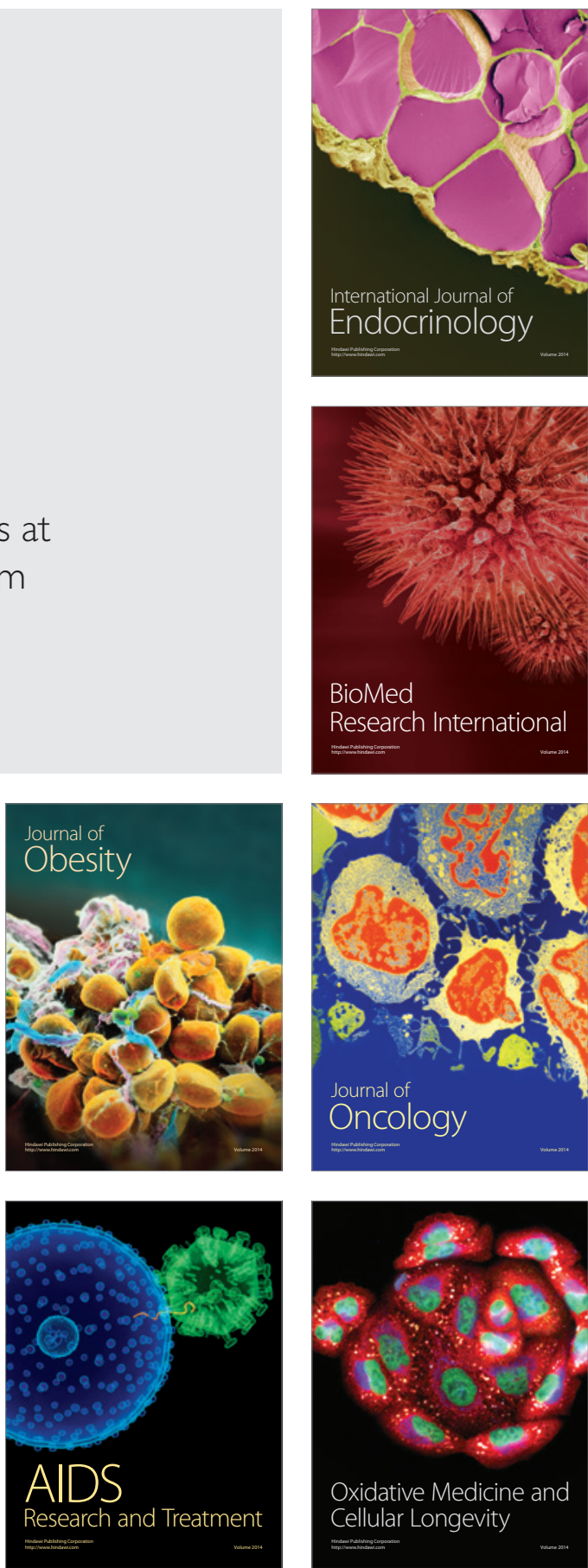